\title{
¿Es cáncer, doctor?
}

\section{Is it cancer, doctor?}

\section{Sergio Gabriel Carbia ${ }^{1}$ y Agostina Rodríguez Scarso ${ }^{2}$}

\author{
1 Docente Adscripto de Dermatología \\ ${ }^{2}$ Médica Especialista en Dermatología \\ Universidad de Buenos Aires, Ciudad Autónoma de Buenos \\ Aires, Argentina
}

Contacto del autor: Sergio Gabriel Carbia

E-mail: sergiocarbia67@gmail.com

Fecha de trabajo recibido: $30 / 3 / 2020$

Fecha de trabajo aceptado: 20/5/2020

Conflicto de interés: los autores declaran que no existe conflicto de interés.

Dermatol. Argent. 2020, 26 (2): 91-92
A la mañana siguiente, cuando Norma se despertó, Macky ya se habia ido a trabajar. Bostezó y fue al cuarto de baño, y mientras estaba leyendo el Buenos días, soy Dios se miró en el espejo. "Dios mio! ¡Tenía la nariz llena de puntitos rojos brillantes! Oh, Señor". Bueno, pues ahi estaba. El dia habia llegado por fin: tenia cáncer de nariz. Se sentó al instante en el suelo para no golpearse la cabeza si se desmayaba. Oh, no, seguramente tendrian que extirparle la nariz entera. Iba a quedar desfigurada. "PPor qué yo, Dios mio? ¿Por qué mi cara?", pensó Norma. En el instituto, Norma no tuvo jamás ni una pizca de acné, ni un bultito. Ahora recibia el castigo por ello. Se puso de pie y miró otra vez. ¡Todavia estaban abi! No solo perdería la nariz, sino que quizá necesitaría quimioterapia. jAdiós a todo el pelo! Oh, Dios. "Sé valiente", pensó. Aterrada, llamó al dermatólogo, concertó una cita y se dirigió al salón de belleza. Entró de golpe.

-Tot, dame uno de esos Xanax. ;A lo mejor tienen que extirparme la nariz!

Más tarde, mientras el doctor Steward le examinaba detenidamente la nariz con una lupa, Norma sintió ganas de vomitar.

—Digame, señora Warren — dijo el médico-, ¿se ruboriza usted fácilmente?

- ¿Qué? Oh, sí.

- Ajá - dijo el médico mientras a ella el corazón le latía con fuerza- ¿Y sabe si tiene alguna alergia?

-No, aparte quizá de la comida china..., se me pone la cara caliente y colorada, pero...

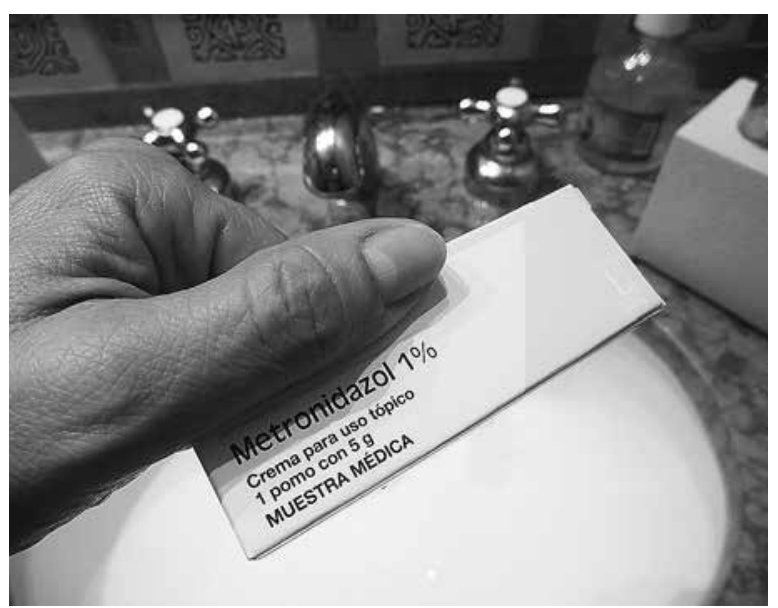

El médico se volvió para lavarse las manos y Norma se oyó a si misma preguntar con voz áspera:

— ¿Es cáncer, doctor?

El médico la miró.

-No, lo que tiene usted es rosácea.

- ¿Qué?

-Rosácea. Es muy común entre los ingleses, los irlandeses y otras personas de piel clara. Ruborizarse con facilidad es uno de los sintomas.

- ¿Ah, si? Creia que simplemente era timida o me azoraba. Y estos bultitos, ¿qué son?

- Le están saliendo granos.

- Pero ¿por qué?

- Puede ser por diversas causas..., el calor, el sol, el estrés. ¿Últimamente ha estado más estresada de lo habitual? 
FANNIE FLAGG (ESTADOS UNIDOS, 1944)

Nacida en Birmingham, Alabama, con el nombre de Patricia Neal, se dio a conocer por su participación en el programa de concursos Match Game en las décadas de 1970 y 1980 . A los 14 ańos ya actuaba en un grupo de teatro y a los 19 escribía y producía guiones para programas de televisión, lo que supuso un desafío porque, debido a su dislexia, nunca supo deletrear. En cuanto a su cambio de nombre, Fannie Flagg, sucedió de manera obligada al ser un requisito de inscripción en el sindicato de actores y directores de teatro.

De su obra literaria resaltan: Daisy Fay y el hombre de los milagros (1983), Tomates verdes fritos en el café de Whistle Stop (1987), que le otorgó fama mundial al coguionarla en película en 1991, lo que le valió la nominación al premio Oscar de la Academia de Hollywood, Bienvenida a este mundo pequeña (1998), Me muero por ir al cielo (2006) y Todavía sueño contigo (2010).

Me muero por ir al cielo es una novela que transcurre en el pueblo de Elmwood Springs a partir de un día de verano en que la anciana Elner cae de lo alto de una escalera. Una vez en el hospital, la octogenaria vive encuentros extraordinarios con sus personas más cercanas, y al estilo de una comedia coral de enredos, la autora hábilmente nos muestra la vida de gente sencilla que, finalmente, cavilará ante la antigua, pero siempre vigente cuestión: “¿Por qué estamos aquí?”.

Se han recopilado múltiples frases de la autora, entre las que se destacan: "Ser una persona exitosa no es necesariamente definido por lo que conseguiste, sino por lo que superaste”, “'Sabes? Un corazón puede estar roto, pero aún sigue latiendo", "Quienes más sufren son quienes menos lo dicen" y "Recuerda que si la gente habla detrás de tu espalda jsolo significa que tú estás dos pasos por delante!".

\section{BIBLIOGRAFÍA}

Flagg F. ¡Cuestión de narices! En: Flagg F. Me muero por ir al cielo, 1. ${ }^{\mathrm{a}}$ ed, Vergara, Buenos Aires, 2006:281-283.

\section{PERLAS}

\section{Federico Pastore}

Médico Dermatólogo y Legista. Médico de Planta de Dermatología, Hospital Dr. Enrique Tornú. Jefe del Servicio de Dermatología, Instituto César Milstein

\section{DERMATITIS ATÓPICA. COMORBILIDADES}

Los pacientes con dermatitis atópica pueden desarrollar otras comorbilidades alérgicas, así como infecciones bacterianas y virosis cutáneas y extracutáneas, en ocasiones severas. Con menor frecuencia, se señalan otras patologías que deben investigarse, como afecciones neuropsiquiátricas: ansiedad, depresión; obesidad, diabetes tipo 2; cardiopatías: infarto de miocardio, coronariopatías; neoplasias, en especial linfomas; enfermedades autoinmunes: gastroenteritis inmunes, enfermedad de Crohn, colitis ulcerosa, celiaquía; alopecia areata.

Paller A, Jaworski JC, Simpson EL, Boguniewicz M, et ál. Major comorbidities of atopic dermatitis: beyond allergic disorders. Am J Clin Dermatol 2018;19:821-838.

\section{COMORBILIDADES: COMPROBADAS U OCASIONALES}

Revisión de estadísticas de cinco patologías. La dermatitis atópica se asocia con linfomas; en ocasiones, con cáncer del páncreas. La hidroadenitis supurativa, con depresión y ansiedad. En la alopecia areata deben investigarse las tiroideopatías. La urticaria crónica se asocia con enfermedades inflamatorias (sinusitis crónica, otitis media, periodontitis, diverticulitis, Helycobacter pylori, úlcera péptica, hepatitis $B \circ \mathrm{C}$ ). El pénfigo paraneoplásico se asocia con enfermedades pulmonares, bronquiolitis obliterante, enfermedad pulmonar obstructiva crónica y enfermedades linfoproliferativas.

Qureshi A, Friedman A. Comorbidities in dermatology. What's real and what's not. Dermatol Clin 2019;37:65-71.

\section{HIPERQUERATOSIS. SULFURO DE SELENIO}

Tanto las formas congénitas como las adquiridas son tratadas con queratolíticos (urea, ácido salićlico, ácido láctico), retinoides (acitretina), corticosteroides tópicos o fototerapia (PUVA). El sulfuro de selenio, en loción o champú al 2,5\% 0 en espuma al 2,75\%, masajeado durante 10 minutos (20 minutos a 2 horas en casos severos), eliminado con agua y secado es eficaz, sobre todo, en localizaciones palmares o plantares.

Cohen PR, Anderson CA. Topical selenium sulfide for the treatment of hyperkeratosis. Dermatol Therap 2018:8:639-649.

\section{CUERO CABELLUDO SENSIBLE. CAUSAS}

El cuero cabelludo sensible es una reacción anormal y desagradable a estímulos ambientales. Se manifiesta por prurito, cosquilleo, dolor 0 sensación de quemazón ("Doctor, me pica la cabeza"). No hay signos de inflamación ni lesiones. Es diferente de la pitiriasis simple ("caspa"). Las causas son rotura de la barrera cutánea, cantidad y calidad alterada del sebo y microbioma alterado. A veces, esta es la única causa y predominan Propionibacterium y estafilococos.

Ma L, Guichard A, Cheng Y, Li I, etál. Sensitive scalp is associated with excessive sebum and perturbed microbiome. J Cosmet Dermatol 2019;18:922-928.

\section{QUERATOSIS ACTÍNICA. ESTUDIO COMPARATIVO}

Estudio estadístico exhaustivo de 624 pacientes con cinco 0 más queratosis actínicas, que afectaban un área de 25 a $100 \mathrm{~cm}^{2}$ en la cabeza. Los tratamientos fueron 5-fluorouracilo al $5 \%$ (155), imiquimod al 5\% (156), terapia fotodinámica con metilaminolevulinato (156) y gel de ingenol mebutato (157). Al cabo de 12 meses de seguimiento, la crema de 5-fluorouracilo al $5 \%$ fue más efectiva que la crema de imiquimod al 5\%, la terapia fotodinámica o el gel de ingenol mebutato.

Jansen MHE, Kessels JPHM, Nelemans PJ, Kouloubis N, etál. Randomized trial of four treatment approaches for actinic keratosis. N Engl J Med 2019;380:935. 